\title{
Corifollitropin alfa for poor responders patients, a prospective randomized study
}

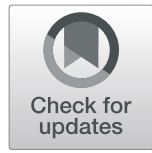

F. M. Fusi ${ }^{*}$ (D) L. Zanga, M. Arnoldi, S. Melis, M. Cappato, I. Candeloro and A. Di Pasqua

\begin{abstract}
Background: Poor ovarian response remains one of the biggest challenges for reproductive endocrinologists. The introduction of corifollitropin alpha (CFA) offered an alternative option to other gonadotropins for its longer halflife, its more rapid achievement of the threshold and higher FSH levels. We compared two different protocols with CFA, a long agonist and a short antagonist, and a no-CFA protocol.

Methods: Patients enrolled fulfilled at least two of the followings: $\mathrm{AFC}<5, \mathrm{AMH}<1,1 \mathrm{ng} / \mathrm{ml}$, less than three oocytes in a previous cycle, age $>40$ years. Ovarian stimulation with an antagonist protocol was performed either with $300 \mathrm{UI}$ rFSH and $150 \mathrm{UI}$ rLH or $300 \mathrm{UI} \mathrm{HMG}$. In the long agonist group, after pituitary suppression with triptorelin, CFA was given the 1-2th day of cycle and $300 \mathrm{UI}$ rFSH and $150 \mathrm{UI}$ rLH the 5th day. In the short antagonist group CFA was given the 1-2th day of cycle and $300 \mathrm{UI}$ rFSH and $150 \mathrm{UI}$ rLH the 5th day. The primary objective was the effect on the number of oocytes and MII oocytes. Secondary objective were pregnancy rates, ongoing pregnancies and ongoing pregnancies per intention to treat.

Results: The use of CFA resulted in a shorter lenght of stimulation and a lower number of suspended treatments. Both the CFA protocols were significantly different from the no-CFA group in the number of retrieved oocytes $(p<0,05)$, with a non-significant difference in favour of the long agonist protocol. Both CFA groups yielded higher pregnancy rates, especially the long protocol, due to the higher number of oocytes retrieved $(p<0,05)$, as implantation rates did not differ. The cumulative pregnancy rate was also different, due to the higher number of cryopreserved blastocysts $(p<0,02)$.
\end{abstract}

Conclusions: The long agonist protocol with the addition of rFSH and rLH showed the best results in all the parameters. A short antagonist protocol with CFA was less effective, but not significantly, although provided better results compared to the no-CFA group. We suggest that a long agonist protocol with CFA and recombinant gonadotropins might be a valuable option for poor responders.

Trial registration: The study was approved by the local Ethics Committee (EudraCT2015-002817-31).

Keywords: Corifollitropin alfa, Agonist, Antagonist, Poor responders

\footnotetext{
* Correspondence: ffusi@asst-pg23.it

Division of Reproductive Endocrinology, ASST Papa Giovanni XXIII, Piazza

OMS 1, 24127 Bergamo, Italy

(c) The Author(s). 2020 Open Access This article is licensed under a Creative Commons Attribution 4.0 International License, which permits use, sharing, adaptation, distribution and reproduction in any medium or format, as long as you give appropriate credit to the original author(s) and the source, provide a link to the Creative Commons licence, and indicate if changes were made. The images or other third party material in this article are included in the article's Creative Commons licence, unless indicated otherwise in a credit line to the material. If material is not included in the article's Creative Commons licence and your intended use is not permitted by statutory regulation or exceeds the permitted use, you will need to obtain permission directly from the copyright holder. To view a copy of this licence, visit http://creativecommons.org/licenses/by/4.0/ The Creative Commons Public Domain Dedication waiver (http://creativecommons.org/publicdomain/zero/1.0/) applies to the data made available in this article, unless otherwise stated in a credit line to the data.
} 


\section{Background}

Poor ovarian response remains one of the biggest causes of poor outcome in women undergoing ovarian stimulation, with a prevalence ranging from 9 to 24\% [1]. Although in the literature a wide range of protocols using different doses and types of gonadotrophins to manage this particular cohort of patients have been proposed, to date the most efficient treatment for such a kind of patients is still unknown. Hence, the search for the best ovarian stimulation protocol for patients identified as 'poor responders' still continues [2-4].

At first, the definition of poor responder has been a confounding matter, in that different criteria were used by reserchers. In any case, all the studies showed how pregnancy rates in poor ovarian responders remained substantially low [5]. In 2001 the definition of poor responders has been uniformed with the introduction of Bologna criteria [6], but still all the studies in patients fulfilling the Bologna criteria resulted in very low pregnancy rates, irrespective of patients' age and type of ovarian stimulation protocol $[4,7]$.

One of the few stimulation protocols demonstrating promising pregnancy rates in these women is the administration of corifollitropin alfa (CFA) followed by highly purified human menopausal gonadotropin (hpHMG) in a gonadotropin-releasing hormone $(\mathrm{GnRH})$ antagonist protocol [8].

Corifollitropin alfa is a recombinant dimeric glycoprotein, obtained fusing recombinant FSH with the carboxyterminal peptide of beta subunit of hCG. This fusion determines a half-life longer than $\mathrm{FSH}$, a more rapid achievement of the threshold ( $24 \mathrm{~h}$ vs $48 \mathrm{~h}$ ), and a higher level of FSH [9].

Recently, CFA has also been used with GnRH agonists, either in long protocol or with flare up protocol [10-12]. The rationale of the use of CFA in poor responders is related to its more precocious achievement of the threshold and to its higher level of FSH, that might allow the recruitment of a higher percentage of the few available follicles in these patients.

The present study was initiated with the aim of investigating whether the use of CFA, in association with recombinant FSH and LH, could be a useful tool for ovulation induction in poor responder patients, in a prospective randomized trial. In addition, the study evaluated the differences of the use of CFA in a long agonist, a short antagonist, both compared to cycles in which CFA was not utilized.

The study is a prospectic randomized, IRB approved study.

\section{Methods}

\section{Study design}

The study was a prospective, randomized, open study, performed from March 2016 to June 2019. For randomization, the criterion of allocation to each arm of the treatment was a computer-generated randomization sheet of the patients fulfilling the inclusion criteria. Patients were recruited in a ratio 1: 1 respectively for group A (controls without the use of CFA), B (long agonist group with the use of CFA) and $C$ (Antagonist group with the use of CFA).

\section{Inclusion criteria}

Patients who fulfilled at least two of the following criteria were admitted:

- Antral follicle count (AFC) $<5$

- Antimullerian hormone (AMH) $<1,1 \mathrm{ng} / \mathrm{ml}$

- Less than three oocytes obtained in the previous cycle

- Age $>40$ years

\section{Exclusion criteria}

- FSH $>20$

- IV stage Endometriosis

- Severe male factor

- Body mass index $(\mathrm{BMI})<18$ or $>30$

\section{Sample size}

A total of 409 patients were enrolled in this study, and after randomization 136 were enclosed in group A, 137 in group B and 136 in group C. All the cases were with fresh embryos, and no PGT was performed. Most of the cases were treated with ICSI, a minority with IVF. The cases with IVF were 16 in group A, 20 in group B and 15 in group C. The embryo transfer was performed fresh in all cases.

\section{Ovulation induction}

Patients were divided into three groups:

a) Antagonist group without the use of CFA (Control)

b) Long agonist with one dose of CFA

c) Antagonist group with one dose of CFA

Group A):

- Administration of recombinant follicle stimulating hormone (rFSH) $300 \mathrm{UI}$ and recombinant luteinizing hormone (rLH) $150 \mathrm{UI}$ or human menopausal gonadotropin (HMG) 300 UI from the $3^{\text {th }}$ day of the cycle

- Administration of a GnRH antagonist when the leading follicle reached $13 \mathrm{~mm}$

- Final trigger using 10,000 UI of human chorionic gonadotropin (hCG) 
Group B):

- Administration of triptorelin 0,1 from the 19th day of previous cycle to the day of final triggering

- Injection of corifollitropin alfa 100 or 150 based upon weight the 1st or 2nd day of the cycle

- Administration of rFSH 300 UI and rLH 150 UI from the 5th day after CFA injection

- Final trigger using 10,000 UI of hCG

Group C):

- Injection of corifollitropin alfa 100 or 150 based upon weight the 1st or 2nd day of the cycle

- Administration of rFSH 300 UI and rLH 150 UI from the 5th day after CFA injection.

- Administration of a GnRH antagonist when the leading follicle reached $13 \mathrm{~mm}$

- Final trigger using 10,000 UI of hCG

In this study no blind steps were performed.

\section{Objectives}

The primary objective of this study was the evaluation of the effect of CFA addiction on the number of total oocytes and MII oocytes retrieved in poor responder patients undergoing in vitro fertilization. Secondary outcomes were pregnancy rate, ongoing pregnancy rate and ongoing pregnancies per Intention to treat.

\section{Statistical analysis}

Descriptive statistics were obtained for all the parameters. Mean and standard deviation were used for all quantitative parameters. Continuous variables were compared with the use of independent $t$-test. Differences between percentages were studied using Chi-square test generalized to the comparison of several proportions. The level of significance was set at $p<0.05$.

The study was approved by the Local Ethics Committee (EudraCT 2015-002817-31, Deliberation 1400/2015), and Informed consent was obtained from all enrolled patients.

\section{Results}

A comparison was done between the use of corifollitropin plus $\mathrm{rFSH} / \mathrm{rLH}$ both using a long agonist or an antagonist protocol, and the use of an antagonist protocol without CFA with a maximal dose of HMG or $\mathrm{rFSH}$ / rLH (300 UI of FSH activity and 150UI of LH). The maximal dose was chosen due to the expected poor response or on the basis of previous results.

No differences were observed after randomization in the mean age of patients. The use of CFA resulted in a shorter length of stimulation in both CFA groups compared to the control $(p<0,05)$, with a not significant difference between the two CFA groups, although the antagonist CFA was the group with less days of treatment and less controls (Table 1). The number of suspended treatments for lack of response was significantly lower when using CFA for both protocols $(p<0,01 \mathrm{com}$ pared to controls). The group with the long agonist protocol and CFA had the higher values of Estradiol at triggering.

When analyzing results, both CFA protocols were significantly different from the control group in the number of retrieved oocytes, number of MII oocytes and number of embryos $(p<0,05)$, with a non-significant difference in favour of the long protocol (Table 2). Patients who received a long CFA protocol showed a significant difference compared to control group in term of pregnancies, ongoing pregnancies per transfer and ongoing pregnancies per intention to treat $(p<0,05)$. The group that used antagonists and CFA showed a positive trend compared to control, and a negative trend compared to the long agonist CFA, but not significant $(\mathrm{p}<0$, 5 ). The higher number of pregnancies was not due to any effect on the quality of embryos, but to the higher number of oocyte and consequently embryos available for the transfer, as the implantation rate was similar in the three groups (respectively 9,5; 10,3 and 10,2).

Table 1 Patients characteristics

\begin{tabular}{|c|c|c|c|c|}
\hline & Control & Long agonist CFA & Antagonist CFA & \\
\hline $\mathrm{N}$ patients & 136 & 137 & 136 & \\
\hline Mean age & $37,7+2,1$ & $38,2+1,8$ & $38+1,9$ & NS \\
\hline Mean AFC & $3,1+1,2$ & $2,8+0,9$ & $3,1+1,1$ & NS \\
\hline Mean AMH (ng/ml) & $0,7+0,3$ & $0,6+0,2$ & $0,6+0,3$ & NS \\
\hline Days of stimulation & $13,2+3,1$ & $10,2+2,4$ & $9,3+2,1$ & $p<0,05$ \\
\hline Suspended treatments & $16(11,7 \%)$ & $6(4,3 \%)$ & $8(5,9 \%)$ & $p<0,05$ \\
\hline $\mathrm{N}$ of controls & $5,1+1,6$ & $3,8+1,6$ & $3,4+1,2$ & $p<0,05$ \\
\hline E2 at trigger & $846+283$ & $1025+227$ & $985+187$ & $p<0,05$ \\
\hline
\end{tabular}


Table 2 Results of the study

\begin{tabular}{llll}
\hline & Control & Long agonist CFA & Antagonist CFA \\
\hline Retrieved oocytes & $3,6+2,2$ & $5,5+2,3^{*}$ & $4,8+2,1^{*}$ \\
N of Mll oocytes & $2,1+1,6$ & $3,7+1,7^{*}$ & $3,4+1,5^{*}$ \\
N of Embryos & $1,8+0,8$ & $2,9+0,5^{*}$ & $2,5+0,6^{*}$ \\
N of no transfer & $13 / 136(9,5 \%)$ & $6 / 137(4,3 \%)^{* *}$ & $9 / 136(6,6 \%)^{*}$ \\
Pregnancies/transfer & $18 / 123(14,6 \%)$ & $26 / 131(19,8 \%)^{*}$ & $21 / 127(16,5 \%)$ \\
Ongoing pregnancies/transfer & $13 / 123(10,5 \%)$ & $21 / 131(16,1 \%)^{*}$ & $17 / 127(13,4 \%)$ \\
Ongoing pregnancies/lTT & $13 / 136(9,5 \%)$ & $21 / 137(15,3 \%)^{*}$ & $17 / 136(12,5 \%)$ \\
\hline
\end{tabular}

${ }^{*} \mathrm{p}<0,05$ compared to control

${ }^{* *} \mathrm{p}<0,01$ compared to control

Only six of the patients of control group had blastocysts to be vitrified $(4,4 \%)$ with no cumulative pregnancies. In the long agonist group 24 patients had a cryopreserved blastocyst (17,5\%), and in the antagonist CFA 15 patients $(11,1 \%)$. The cumulative pregnancy rate in this two groups, given that not all the patients utilized yet frozen blastocysts, increased respectively to $27,4 \%$ and $21,2 \%$, with an ongoing pregnancy rate of $24,3 \%$ and $19,2 \%$ ( $p<0,01$ compared to cumulative pregnancy rate in controls).

Compared to the previous cycles, in those patients who were not at the first treatment, all the groups had an improvement of the number of oocytes obtained, with a higher significance for the groups that used a long agonist protocol (Table 3). The group that did not use CFA showed a tendential improvement compared to the previous cycle but not significant, probably due to the use of higher doses of gonadotropins.

\section{Discussion}

The best treatment for poor responders has still to be defined. Several studies comparing the GnRH antagonist versus short $\mathrm{GnRH}$ agonist $[13,14]$ or versus long GnRH agonist protocols $[15,16]$ in poor responders showed different and unclear results. A randomized controlled trial comparing the $\mathrm{GnRH}$ antagonist, the long agonist,and the short agonist protocols in poor responders demonstrated that the $\mathrm{GnRH}$ antagonists and the long GnRH agonist were comparable in terms of number of oocytes retrieved, as opposed to the short GnRH agonist protocol that led to inferior results [3].
The introduction of corifollitropin alpha opened new perspectives for the treatment of poor responders, because it has been shown to reach a peak of circulating levels within 2 days, whereas daily FSH does it after 3-5 days, and an higher level over the threshold [17]. This is advantageous for CFA compared to $\mathrm{rFSH}$ in that follicular recruitment depends upon the starting dose and cannot be modified by increasing FSH dose after 5 days. The results of the use of CFA in poor responders were very controversial, probably due to the small numbers of enrolled patients, and the different criteria used to define a poor responder. A pilot study with the use of CFA in an antagonist protocol has shown that ongoing pregnancy rates are low in these women, similar to the treatment with a short agonist protocol [8]. In a multicenter study, Drakopulos showed that CFA and HMG did not give any advantage in young poor responders compared to $\mathrm{rFSH}$ [18]. On the contrary, CFA followed by hpHMG in a GnRH antagonist protocol resulted in promising pregnancy rates in poor ovarian responders $<40$ years of age in a study of Polyzos [19]. Another recent observational cohort study demonstrated that in women with a low AFC, the number of oocytes retrieved is comparable between CFA and daily rFSH [20].

In this study, we added recombinant FSH and $\mathrm{LH}$, at the 2:1 ratio, to corifollitropin alfa. The beneficial effect of such a protocol can be linked to a combined effect of both corifollitropin alfa and recombinant gonadotropins. Corifollitropin alpha is able to reach the threshold rapidly, with a circulating level of FSH well above it, thus allowing a wider recruitment of follicles [8]. rFSH from

Table 3 Comparison with the results of previous cycles

\begin{tabular}{lllll}
\hline & Previous cycles & Control & Long agonist CFA & Antagonist CFA \\
\hline Number of patients & & 32 & 38 & 36 \\
Mean collected oocytes & $2,8+1,3$ & $3,1+1,1^{\circ}$ & $5,21+1,6^{*}$ & $3,8+0,9^{* *}$ \\
Mean MII oocytes & $2,1+0,8$ & $2,2+1,1^{\circ}$ & $4,64+0,6^{*}$ & $2,7+1,1^{\circ}$ \\
Mean Embryos obtained & $1,3+0,4$ & $1,5+0,3^{\circ}$ & $4,2+0,5^{*}$ & $2,3+0,6^{* *}$ \\
\hline
\end{tabular}

${ }^{*}=p<0,01$ compared to previous cycles

${ }^{* *}=\mathrm{p}<0,05$ compared to previous cycles

${ }^{\circ}=$ Not significant 
the 5th day from CFA, the day when circulating level star to decrease, was given to maintain the FSH effect and $\mathrm{rLH}$ was added to complete maturation of oocytes, although its role is still controversial, and to improve endometrial receptivity $[21,22]$.

The studies performed with CFA in long agonists protocols $[12,17]$, showed that CFA can be safely used in normal and poor responders. The use of antagonist protocols or long agonist protocols in poor responders show comparable results, better than those observed with short agonist protocols [3]. Our study was designed to evaluate the effect of addition of CFA in a long agonist or short antagonist protocol on oocyte yield in poor responders, when recombinant gonadotropins were added from the fifth day, earlier than usual protocols. Our data suggest that the long agonist protocol with CFA and the addition of $\mathrm{rFSH} / \mathrm{rLH}$ from the fifth day obtain the best results, both in the number of retrieved oocytes and in fertilization rate. It was observed a significant increase in pregnancy, ongoing pregnancy and cumulative pregnancy rates. This increase seems not to be due to an improvement of the oocyte quality, but simply to the higher number of oocytes obtained, but further studies are needed. The fact that the number of cycles suspended for lack of response was significantly lower compared to controls resulted in a significant difference in number of ongoing pregnancies per intention to treat. The antagonist protocol with CFA yielded inferior results, although better than cycles with antagonists without CFA.

\section{Conclusions}

We suggest that CFA in a long agonist protocol can be an interesting approach for poor responders. The addition of recombinant gonadotropins to corifollitropin alfa is also a new approach for these patients, both in a long agonist and a short antagonist protocol. The strength of this study is related to the number of patients enrolled, all poor responders based on previous cycles or markers of ovarian reserve, and to the fact that it was a prospective, randomized study.

\section{Acknowledgements}

We thank the clinical staff of the Reproductive endocrinology unit, doctors and embryologists, for their help in the clinical work that made possible this study.

\section{Authors' contributions}

All authors were involved in the clinical work. ZL and CM worked in the extraction of data from the data base. FF, Cl and DPA performed the analysis of data and statistics. FF was involved in writing the manuscript, with the collaboration of AM, MS and ZL. All authors read and approved the final manuscript.

\section{Funding}

The funding for analyzing the data and writing the manuscript were obtained from the budget for Division of the Hospital Papa Giovanni XXIII.

\section{Availability of data and materials}

All data generated or analysed during this study are included in this published article.

\section{Ethics approval and consent to participate}

The study was approved by the Local Ethics Committee and authorization for the use of anonymized data was obtained from each patient involved. All procedures performed in studies involving human participants were in accordance with the ethical standards of the institutional and/or national research committee and with the 1964 Helsinki declaration and its later amendments or comparable ethical standards.

The Ethics Committee of Provincia di Bergamo approved the study (EudraCT 2015-002817-31, Deliberation 1400/2015).

\section{Consent for publication}

"Not applicable".

\section{Competing interests}

The authors declare that they have no competing interests.

Received: 8 April 2020 Accepted: 30 June 2020

Published online: 09 July 2020

\section{References}

1. Ubaldi F, Vaiarelli A, D'Anna R, Rienzi L. Management of Poor Responders in IVF: is there anything new? Biomed Res Int. 2014;2014:1-10.

2. Polyzos NP, Devroey P. A systematic review of randomized trials for the treatment of poor ovarian responders: is there any light at the end of the tunnel? Fertil Steril. 2011;96:1058-61.

3. Sunkara SK, Coomarasamy A, Faris R, Braude P, Khalaf Y. Long gonadotrophin-releasing hormone agonist versus short agonist versus antagonist regimens in poor responders undergoing in vitro fertilization: a randomized controlled trial. Fertil Steril. 2014;101:147-53.

4. Polyzos NP, Nwoye $M$, Corona $R$, et al. Live birth rates in Bologna poor responders treated with ovarian stimulation for IVF/ICSI. Reprod BioMed Online. 2014;28:469-74.

5. El-Toukhy $T$, Khalaf $Y$, Hart $R$, et al. Young age does not protect against the adverse effects of reduced ovarian reserve -- an eight year study. Hum Reprod. 2002;17:1519-24

6. Ferraretti AP, La Marca A, Fauser BC, et al. ESHRE consensus on the definition of 'poor response' to ovarian stimulation for in vitro fertilization: the Bologna criteria. Hum Reprod. 2011;26:1616-24.

7. Busnelli A, Papaleo E, Del Prato D, et al. A retrospective evaluation of prognosis and cost-effectiveness of IVF in poor responders according to the Bologna criteria. Hum Reprod. 2015:30:315-22.

8. Polyzos NP, De Vos M, Corona R, Vloeberghs V, Ortega-Hrepich C, Stoop D, Tournaye $\mathrm{H}$. Addition of highly purified HMG after corifollitropin alfa in antagonist-treated poor ovarian responders: a pilot study. Hum Reprod. 2013:28:1254-60.

9. Verbost P, Sloot WN, Rose UM, de Leeuw R, Hanssen RG, Verheijden GF. Pharmacologic profiling of corifollitropin alfa, the first developed sustained follicle stimulant. Eur J Pharmacol. 2011 Jan 25;651(1-3):227-33.

10. Fatemi HM, Oberyé J, Popovic-Todorovic B, Witjes H, Mannaerts B, Devroey $\mathrm{P}$. Corifollitropin alfa in a long $\mathrm{GnRH}$ agonist protocol: proof of concept trial. Fertil Steril. 2010;94(5):1922-4.

11. Joaquin Errázuriz, Panagiotis Drakopoulos, David Pening1, Annalisa Racca, Alessia Romito, Nelke De Munck, Herman Tournaye, Michel De Vos, Christophe Blockeel. Pituitary suppression protocol among Bologna poor responders undergoing ovarian stimulation using corifollitropin alfa: does it play any role? RBMO 2019 38;6:1010-1017.

12. Haydardedeoğlu B, Kılıçdağ EB. A novel approach using a minimal number of injections during the IVF/ICSI cycle: luteal half-dose depot GnRH agonist following corifollitropin alfa versus the corifollitropin alfa with a $\mathrm{GnRH}$ antagonist cycle. J Turk Ger Gynecol Assoc. 2016 Sep 1;17(3):155-8.

13. Griesinger G, Diedrich K, Tarlatzis BC, Kolibianakis EM. GnRH-antagonists in ovarian stimulation for IVF in patients with poor response to gonadotrophins, polycystic ovary syndrome, and risk of ovarian hyperstimulation: a meta-analysis. Reprod BioMed Online. 2006;13:628-38.

14. Lainas TG, Sfontouris IA, Papanikolaou EG, Zorzovilis JZ, Petsas GK, Lainas GT, Kolibianakis EM. Flexible GnRH antagonist versus flare-up $\mathrm{GnRH}$ agonist 
protocol in poor responders treated by IVF: a randomized controlled trial. Hum Reprod. 2008;23:1355-8.

15. Cheung L-P, Lam P-M, Lok IH, Chiu TT-Y, Yeung S-Y, Tjer C-C, Haines CJ. $\mathrm{GnRH}$ antagonist versus long $\mathrm{GnRH}$ agonist protocol in poor responders undergoing IVF: a randomized controlled trial. Hum Reprod. 2005;20:616-21.

16. Pu D, Wu J, Liu J. Comparisons of GnRH antagonist versus $\mathrm{GnRH}$ agonist protocol in poor ovarian responders undergoing IVF. Hum Reprod. 2011;26: 2742-9.

17. Fauser BCJM, Alper MM, Ledger W, Schoolcraft WB, Zandvliet A, Mannaerts BMJL. Pharmacokinetics and follicular dynamics of corifollitropin alfa versus recombinant FSH during ovarian stimulation for IVF. Reprod BioMed Online. 2010;21:593-601

18. Polyzos NP, DeVos M, Humaidan P, Stoop D, Ortega-Hrepich C, Devroey P, Tournaye H. Corifollitropin alfa followed by rFSH in a GnRH antagonist protocol for poor ovarian responder patients: an observational pilot study. Fertil Steril. 2013;99:422-6.

19. Drakopoulos P, Vuong TNL, Ho NAV, Vaiarelli A, Ho MT, Blockeel C, Camus M, Lam AT, van de Vijver A, Humaidan P, Tournaye H, Polyzos NP. Corifollitropin alfa followed by highly purified HMG versus recombinant FSH in young poor ovarian responders: a multicentre randomized controlled clinical trial. Hum Reprod. 2017;32:2225-33.

20. Yovich J, Keane KN, Borude G, Dhaliwal SS, Hinchliffe PM. Finding a place for corifollitropin within the PIVET FSH dosing algorithms. Reprod BioMed Online. 2018;36:47-58.

21. Bosch E, Labarta E, Crespo J, et al. Impact of luteinizing hormone administration on gonadotropin-releasing hormone antagonist cycles: an age-adjusted analysis. Fertil Steril. 2011;95:1031-6.

22. Sacchi S, Sena P, Degli Esposti C, Lui J, La Marca A. Evidence for expression and functionality of FSH and LH/hCG receptors in human endometrium. J Assist Reprod Genet. 2018 Sep;35(9):1703-12.

\section{Publisher's Note}

Springer Nature remains neutral with regard to jurisdictional claims in published maps and institutional affiliations.

Ready to submit your research? Choose BMC and benefit from:

- fast, convenient online submission

- thorough peer review by experienced researchers in your field

- rapid publication on acceptance

- support for research data, including large and complex data types

- gold Open Access which fosters wider collaboration and increased citations

- maximum visibility for your research: over $100 \mathrm{M}$ website views per year

At $\mathrm{BMC}$, research is always in progress.

Learn more biomedcentral.com/submissions 